\title{
En tredje vej for teologisk etik?
}

\author{
Professor dr.theol. \\ Svend Andersen
}

Ulrik Becker Nissen, Between Universality and Specificity. A Study of Christian Social Ethics with Particular Emphasis on Dietrich Bonhoeffer's Ethics. Aarhus Universitet 2014. ${ }^{1}$

\begin{abstract}
The article is a review of Ulrik B. Nissen's higher doctoral degree thesis, which deals with Bonhoeffer's ethics seen within the Lutheran tradition. By means of the exposition of Luther's and Bonhoeffer's ethical thoughts, Nissen aims at formulating a third position between universality and specificity, particularly in regard to the role of Christian/religious arguments in public discourse. As a conceptual instrument for grasping the theological foundation of the alleged third way, Nissen uses Chalcedonian Christology and communicatio idiomatum. The reviewer claims that even if there is, in Lutheran ethics, a combination of a specific Christian and a universal dimension - the latter consisting in natural law theory - it does not contribute to a deeper understanding to interprete this combination as a manifestation of the intertwinement of the two natures of Christ.
\end{abstract}

Key Words: Theological ethics - Martin Luther - Dietrich Bonhoeffer universalism vs. particularism - religion in public debate.

I 2014 forsvarede Ulrik B. Nissen sin afhandling for den teologiske doktorgrad ved Aarhus Universitet. Ifølge Bekendtgørelse om doktorgrader kan en doktorafhandling bestå af "flere afhandlinger" og det er tilfældet her. Der er ikke tale om en monografi, men om en såkaldt Sammenfattende redegørelse, der ledsager ti publicerede tidsskriftartikler. Redegørelsen er på 138 sider og rummer et dansk Resumé på 10 sider samt en Bibliography på 17 sider. $^{2}$

1. Den følgende artikel er en bearbejdet version af min officielle opposition ved forsvarshandlingen den 7.3. 2014.

2. De publicerede artikler af Ulrik Nissen er: "Between Unity and Differentiation - On the Identity of Lutheran Social Ethics" [= Artikel I], The Sources of Public Morality - On the Ethics and religion debate, red. Ulrik B. Nissen m.fl. (Münster: LIT Verlag 2003), 152-171. - "Reconciliation and Public Law. Christian Reflections about the Sources of Public Law" [II] , StTh 58 (2004), 27-44. - "Letting Reality Become Real. On Mystery and Reality in Bonhoeffer's Ethics" [III], Journal of Religious Ethics 39 (2011), 321-343. - "Dietrich Bonhoeffer and the Ethics of Plenitude" 
En afhandling af denne karakter er en lidt besværlig genre for læseren. Der er dels en række selvstændige artikler, som i dette tilfælde er tematisk beslægtede og præget af en del gentagelser. Dels er der den sammenfattende redegørelse, omfattende metode og forskningsoversigt, men også en præsentation af de publicerede artikler samt ganske udførlig redegørelse for den grundlæggende problemstilling. For at give et dækkende billede af afhandlingen er det i det følgende nødvendigt at citere fra både den sammenfattende redegørelse og de særskilt publicerede artikler.

\section{Afhandlingens diskussionskontekst}

Ulrik Nissens afhandling kan karakteriseres på forskellig måde. Som titlen angiver, er den et bidrag til forståelsen af Dietrich Bonhoeffers etik. Men den beskæftiger sig også med en anden person, der dog ikke er nævnt i titlen, nemlig Martin Luther. Behandlingen af de to teologers tanker er tæt forbundne, idet Nissen tolker Bonhoeffer som luthersk etiker. Hvad Luther angår, tager Nissen de centrale temaer i hans socialetik op, så som sondringen mellem åndeligt og verdsligt, øvrighedens status og grundlag, de tre stænder og den naturlige lov. Allerede i forbindelse med Luther formulerer Nissen sin hovedtese: $i$ Luthers teologiske etik er der ikke en klar adskillelse af en universalistisk og en partikularistisk tilgang. De to dimensioner er derimod tæt forbundne og udgør, hvad der kaldes en differentieret enhed. Og det afgørende teologiske grundlag for denne struktur er givet med den klassiske forståelse af Jesus Kristus: den såkaldte chalkedonensiske kristologi, der indebærer at Kristus på en gang er Gud og menneske, en person med to naturer, ikke sammenblandede og alligevel uadskillelige. $^{3}$

[IV], Journal of the Society of Christian Ethics 26, (2006), 97-114. - "Disbelief and Christonomy of the World" [V], StTh 60 (2006), 91-110. - "The Christological Ontology of Reason" [VI], NZSTh 48 (2006), 460-478. - "Responding to Human Reality. Responsibility and Responsiveness in Bonhoeffer's Ethics" [VII], Being Human, Becoming Human. Dietrich Bonhoeffer and Social Thought, red. J. Zimmerman \& B. Gregor (Eugene, OR: Wipf \& Stock Publishers 2010), 203-225. - "Being Christ for the Other. A Lutheran affirmation of Christian Humanism" [VIII]. StTh 64 (2010), 177-198. - "Responsibility and Responsiveness. Reflections on the Communicative Dimension of Responsibility" [IX]. NZSTh 53 (2011), 90-108. "Social Ethics Between Universality and Specificity: Outline of a Chalcedonian Social Ethic" [X]. Dialog: A Journal of Theology 51 (2012), 83-91.

3. En klassisk fremstilling af den chalkedonensiske kristologi kan findes hos en af Aarhusteologiens fædre: Regin Prenter, Skabelse og genløsning (København: G.E.C. 
Hvad Bonhoeffer angår, finder Nissen den samme chalkedonensiske struktur i martyrteologens afvisning af "torumstænkning", hvor han på barthiansk vis hævder, at Kristus er nærværende i al virkelighed. For Bonhoeffer kan der følgelig ikke findes nogen socialetik eller politisk etik, som er helt uafhængig af et kristologisk aspekt. Hos Bonhoeffer tager Nissen en række specifikke temaer op, så som virkelighed, fornuft og ansvarlighed, der alle - på trods af deres tilsyneladende almenmenneskelige, universelle karakter - hævdes at skulle forstås kristologisk. ${ }^{4}$

En komparativ tolkning af Luthers og Bonhoeffers socialetikker ville være interessant i sig selv. Men Nissens anliggende er mere vidtgående end som så. Han placerer tolkningen af Luther og Bonhoeffer inden for konteksten af to vigtige debatter i nutidig etik, to debatter der hverken er identiske eller helt adskilte.

Den første debat vedrører det meget overordnede spørgsmål om karakteren af det normative grundlag for den politiske orden. Findes der sådan noget som politisk-etiske principper, der er begrundet i en almen fornuft, og som derfor har universel gyldighed? Et bekræftende svar kan vi fx finde hos Immanuel Kant. Efter hans mening findes der én praktisk menneskelig fornuft, der er grundlag for et basalt etisk princip, det kategoriske imperativ, og et tilsvarende retsprincip. Den kantiske tankegang er i vores tid blevet taget op af de to mest fremtrædende politiske filosoffer, John Rawls og Jürgen Habermas. Hos Habermas finder vi ganske vist antydningsvis en alternativ position, idet han inspireret af Hegel skelner mellem moral og etik. Hvor moral hos Habermas er en normativitet med universel gyldighed, består etik af et partikulært fællesskabs værdier. Interessant nok er der for Habermas ikke noget problematisk ved, at der i en stat træffes politiske beslutninger både på moralsk og etisk grundlag. ${ }^{5}$

Alternativet til den kantiske universalisme finder vi i den såkaldte kommunitarisme, der måske har den katolske, irsk-amerikanske filosof Alister MacIntyre som den mest fremtrædende repræsentant. Kommunitarister hæuder, at en stat kun kan have tilstrækkelig sammenhængskraft, hvis den er præget af en bestemt tradition, historie

Gad 1967), 370f.

4. Se artikel III, VI og VII.

5. Forskellen mellem moral og etik er grundlæggende i Habermas' politiske filosofi, se fx Jürgen Habermas, Faktizität und Geltung. Beiträge zur Diskurstheorie des Rechts und des demokratischen Rechtsstaats (Frankfurt: Suhrkamp 1992) 139. Om forholdet mellem Habermas' og Rawls' politiske filosofi og deres opfattelse af religionens rolle se Svend Andersen, Macht aus Liebe. Zur Rekonstruktion einer lutherischen politischen Ethik (Berlin/New York: De Gruyter 2010), $245 \mathrm{ff}$. 
og kultur, som indeholder de værdier, der er bindende for netop dette partikulære fællesskab. ${ }^{6}$

Forskellen mellem de to positioner består således i, at vi på den ene side har ideen om rationelt begrundede principper, der er universelle i betydningen gyldige for alle fornuftige mennesker - og på den anden side værdier, der kun er bindende for medlemmer af et bestemt fællesskab. Forskellen mellem universalisme og partikularisme er her en forskel i henseende til rækkevidde eller omfang: er normerne og værdierne bindende for alle eller kun for nogle? Men det er også en forskel i henseende til begrundelse: er normerne funderede i den ene og samme menneskelige fornuft - eller i specifikke traditioner, der per definition er af begrænset og i sidste ende kontingent karakter?

I Danmark kender vi denne modsætning mellem universalisme og partikularisme fra diskussionen mellem forsvarere for menneskerettigheder og fortalere for såkaldte "danske værdier”. I øvrigt hænger denne diskussion sammen med problemet om etisk absolutisme versus relativisme.

Den anden diskussion, som Nissen placerer sine analyser i, handler om religionens rolle i demokratiske samfunds politiske og offentlige liv. Også her finder vi to modsatrettede positioner. På den ene side den, som undertiden kaldes sekularisme, dvs. den opfattelse, at et demokrati med lige rettigheder til alle borgere ikke kan favorisere nogle bestemte religioner eller livsanskuelser, men tværtimod som stat skal være religiøst neutral og adskilt fra kirken (eller moskeen for den sags skyld). Et kontroversielt spørgsmål i debatten er, om religiøse borgere har ret til at fremføre religiøse argumenter i den offentlige debat om politiske beslutninger. Igen er både Rawls og Habermas vigtige figurer i debatten. - Den modsatte position kan have forskellige former. Man kan hævde, at en politisk orden uden et religiøst eller lignende grundlag er en illusion. Eller man kan mere moderat hævde, at alle slags argumenter er tilladt i den politiske debat, således at politiske beslutninger baseres på en slags kompromiser.

For igen at relatere til vor danske kontekst har vi haft denne slags diskussion efter Muhammed-krisen, da fx tidligere statsminister Anders Fogh Rasmussen skrev sin berømte artikel om, at religionen fyldte for meget i den offentlige debat og dermed truede samfundets sammenhængskraft.

6. Se MacIntyres to klassiske værker After Virtue. A Study in Moral Theory (London: Duckworth 1981/1985) og Whose Justice? Which Rationality? (London: Duckworth 1988).

7. A.F. Rasmussen: "Hold religionen indendørs", i Politiken 20.5. 2006. Se hertil Svend Andersen: "Sammenhængskraften og de to regimenter: Farlig politik og 
På baggrund af de to her nævnte diskussioner kan vi forstå Nissens hovedtese, formuleret på baggrund af den tilsyneladende uudlignelige modsætning mellem etisk universalisme og partikularisme:

Against this backdrop, the present dissertation seeks to promote an understanding of the foundation of social ethics that moves beyond a tendency to separate its universal and its specific dimension. My wish is to contribute to a third position where, in their relation, the universal and specific dimensions of a Christian social ethic are continuously seen as a unity, even as they remain distinct from each other. From this third position's perspective, the universal and specific dimensions rest in a differentiated unity (Nissen 2014, 12).

Nissen finder denne "differentierede enhed" i både Luthers og Bonhoeffers etikker, og han finder grundlaget for tankestrukturen i den chalkedonensiske kristologi. Et afgørende spørgsmål til Nissens afhandling er, hvad denne differentierede enhed helt nøjagtigt indebærer - og hvor meget den kan bidrage med til forståelsen af politisk-etiske debatters status. Ved siden af dette helt overordnede spørgsmål er der en række mere specifikke problemstillinger, som kræver nærmere diskussion. Det drejer sig om hans forståelse af Luthers etik og i den forbindelse forståelsen af den naturlige lov, hans brug af de grundlæggende begreber universalitet og partikularitet osv., samt hans opfattelse af forholdet mellem kristendom og politik.

\section{Teologisk etik, luthersk forstået}

Først skal det imidlertid handle om disciplinen teologisk etik. Dette forhold behandles i afsnit 4.2 i den sammenfattende redegørelse: "Chalcedonian motifs in Luther's theology and ethics" (50-54). Det er imidlertid ikke klart, hvordan sammenhængen skal forstås, for hvad Nissen gør i dette afsnit, er dels at bringe citater fra Luther, dels at citere sekundærlitteratur om Luther. Hvordan han selv opfatter forbindelsen mellem Kristi to naturer og konstitueringen af en kristen etik, er derimod uklart.

uholdbar teologi”, Sammenhangskraften. Replikker til Fogh, red. P. Lodberg (Aarhus: Forlaget Univers 2007), 106-116. 
En af de forfattere, der citeres, er Johann Anselm Steiger, der har skrevet en vigtig artikel om communicatio idiomatum. ${ }^{8}$ Fra denne artikel citeres følgende:

Nicht nur die Christologie allein, sondern auch die Abendmahlslehre, die Anthropologie, die Rechtfertigungslehre, die Schrifthermeneutik, die Rhetorik, die Seelsorgetheologie und die Theologie der Schöpfung (Steiger 1996, 1).

Alle de her opregnede aspekter af teologien er altså for Steiger influerede af læren om communicatio idiomatum. Men faktisk har Steiger i artiklen også et særligt afsnit med overskriften „Die communicatio idiomatum in Luthers Ethik und Poimenik" (Steiger 1996, 13). Det kunne jo synes at være af central betydning for Nissens argumentation, og så meget mere undres man over, at han end ikke omtaler det.

Hovedvidnet for Nissens opfattelse af sammenhængen mellem den chalkedonensiske fundering (dvs. communicatio idiomatum) af kristen etik er imidlertid den svenske Lutherforsker Kjell Ove Nilsson. I dennes bog Simul. Das Miteinander von Göttlichem und Menschlichem in Luthers Theologie hedder det:

Im Verhältnis von Kirche und Welt bedeutet die communicatio idiomatum für den Christen, daß er gleichzeitig in der Kirche lebt, dort die Vergebung der Sünden durch jene Mittel empfängt, die dazu eingerichtet sind, und in der Welt seine Berufsaufgabe ausführt und so gut wie möglich seinem Nächsten zu dienen versucht. Es muß vielleicht unterstrichen werden, daß dieser Beruf und überhaupt das weltliche Regiment für Luther keine christologische Prägung in enggefaßter Bedeutung trägt, denn das müßte heißen, daß man das Menschliche im Göttlichen (...) aufgehen ließe ...9

Nissen behandler Nilssons bog i den publicerede artikel "Between Unity and Differentiation - On the Identity of Lutheran Social Ethics" (artikel I), hvor han tolker Nilsson på følgende måde: "On the basis of faith and baptism the Christian is part of the body of Christ - i.e. the church - while this very same body is embodied in the world. The body of Christ cannot be thought of apart from

8. Johan A. Steiger: "Die Communicatio Idiomatum als Achse und Motor der Theologie Luthers. Der "fröhliche Wechsel" als hermeneutischer Schlüssel zu Abendmahlslehre, Anthropologie, Seelsorge, Naturtheologie, Rhetorik und Humor", NZSTh 38 (1996), 1-28.

9. Kjell Ove Nilsson: Simul. Das Miteinander von Göttlichem und Menschlichem in Luthers Theologie (Göttingen: Vandenhoeck \& Ruprecht 1966), 415. 
the worldly reality" (166). Formuleringen rejser spørgsmålet om selve Nissens forståelse af Luthers skelnen mellem åndeligt og verdsligt, den såkaldte toregimentelære. Nissen hævder, at der består en chalkedonensisk relation mellem de to, men hvad går selve sondringen ud på? Citatet antyder, at åndeligt og verdsligt er ensbetydende med hhv. kirke og verden. Men det er vel ikke alt?

I den samme artikel hedder det, at i det åndelige regimente "love (and not law) is the ruler" (156). Det samme siges i artiklen "Reconcilitation and Public Law. Christian Reflections about the Sources of Public Law" (artikel II, 25). Vil det sige, at kærlighed ikke er "ruler" i det verdslige regimente?

Efter i artikel I at have præsenteret sin læsning af Luthers udlægning af Psalme 82 konkluderer Nissen: "it has become apparent that for Luther the spiritual and the worldly were not thought of as two separate realms" (165). I en fodnote fremhæver han betydningen af den kendsgerning, eftersom "Luther is often seen as leading the way for the separation of religion and politics". I den forbindelse nævnes John Rawls' udsagn "that the historical origins of political liberalism lies in the Reformation and its aftermath". Men er der virkelig en modsætning her - bliver vi ikke nødt til at skelne mellem, hvad Luther siger i sine tekster (og han siger jo ikke altid det samme) - og de historiske virkninger af hans skrifter og handlinger?

\section{Naturlig lov}

Et særdeles vigtigt emne i Luthers etik er den naturlige lov. Også den forstår Luther ifølge Nissen ud fra Chalkedonense og communicatio idiomatum. Således hedder det i det danske Resumé: "I forhold til hans forståelse af den naturlige lov, er det således en grundtanke for Luther, at denne er at forstå som samtidigt guddommelig og naturlig. Ligesom Kristus er samtidig guddommelig og menneskelig, således ville Luther også sige om den naturlige lov" (Nissen 2014, 2). I artikel II, i en diskussion med bl.a. K.E. Løgstrup, modstiller Nissen på den ene side, hvad han kalder et "traditionelt" syn på naturlig lov som "the universal law given with human nature", en "common, universal source of normativity" - og på den anden siden den opfattelse, at begrebet om den naturlige lov er "deeply related to faith" eller er bærer af en "theological qualification" (36f). Han taler også om "simultaneous divine and human dimension of natural law", og at dens "naturalness cannot be separated from its foundation in the will of God" (55). Det er for mig ikke forståeligt, hvad denne kendsgerning 
vedrørende naturlig lov har at gøre med sondringen mellem en universel og en partikulær etik.

Efter min mening kommer Luthers opfattelse af den naturlige lov måske allerbedst til udtryk i en bestemt formulering i slutningen af skriftet Von weltlicher Obrigkeit. Luther rådgiver her en kristen fyrste, der som retshåndhæver skal fælde dom over to stridende parter. Som kristen vil han dømme dem efter "Recht der Liebe", men det kan tænkes, at den ene eller begge ikke vil acceptere det, altså faktisk ikke agerer som kristne. I den situation skal fyrsten sige: „Sie [tun] wider Gott und natürlich Recht ..., ob sie gleich bei Menschenrecht die strenge Schärfe erlangen. Denn die Natur lehret, wie die Liebe tut, daß ich tun soll, was ich mir wollt getan haben" (WA 11, 279). ${ }^{10}$ Den kristne, som tolker den naturlige lov som givet af Gud (partikulært), kan gøre den gældende over for ikke-kristne, fordi den er gyldig for alle (universel). Man kan altså godt sige, at den naturlige lov fra kristentroens synsvinkel indebærer et forhold mellem guddommeligt og (almen)menneskeligt. Men det forekommer uhyre søgt at tolke dette forhold som svarende til guddommeligt-menneskeligt i den chalkedonsiske kristologi. Og bortset fra det: hvad oplyser inddragelsen af Chalkedonense til en teologisk forståelse af den naturlige lov?

\section{Hvad er en "differentieret enhed"?}

Så vidt Nissens opfattelse af Luthers etik. Den centrale tese i afhandlingen vedrører forståelsen af forskellen mellem etisk universalisme og partikularisme ud fra den chalkedonsiske lære om Kristi to naturer. For at udtrykke den fælles struktur i de to sammenhænge bruger Nissen utallige gange vendingen "differentiated unity". En afgørende svaghed ved afhandlingen er, at dette begreb ikke bliver tydeligt bestemt. Begrebet synes i virkeligheden at have flere forskellige betydninger.

En af disse betydninger kunne man kalde enhed i begrundelse. Således taler Nissen om "Foundation of Christian ethics with regard to its universal and specific validity" (Nissen 2014, 26), hvilket man normalt vil forstå sådan, at kristen etik både er begrundet i Guds universelle skabervilje og i frelsen ved Kristus.

En anden betydning er enheden i forstäelsen af den naturlige lov. Nissen forklarer dette sådan, at den naturlige lovs universalitet ikke

10. "de handler mod Gud og den naturlige ret, selv om de opnår den strenge skarphed efter menneskelig ret. For naturen lærer som kærligheden gør: at jeg skal gøre, hvad jeg vil, at der gøres mod mig". 
må føre til ignorering af, at "this universality is derived form a highly specific foundation - the will of God" (59). Som nævnt i forbindelse med Luthers opfattelse af den naturlige lov, er det misvisende at kalde dens begrundethed i Guds vilje som "highly specific". Derimod kan man kalde den kristne eller den troendes overbevisning om, at Gud står bag den naturlige lov for højst specifik.

\section{Kristendom og politik}

En tredje betydning af formuleringen "differentieret enhed" viser sig, når vi kommer til Nissens opfattelse af kristendommens og kristnes rolle $\mathrm{i}$ et nutidigt demokratisk samfund. Her er der tale om noget $\mathrm{i}$ retning af enhed i tolkningen af politiske principper: ifølge Nissen er der fx en balance mellem tilslutningen til et fælles retfærdighedsprincip og det at give dette en specifik kristen kvalifikation. Hvad betyder det? I artikel II hedder det: "For a political society to be considered just, it must be just for every member of the given society" (41, note 6). Hvad betyder "retfærdigt for ethvert medlem"? Ja, hvad er overhovedet et retfærdigt samfund: taler vi som John Rawls om de basale institutioner i samfundet? Formentlig tænker Nissen dog på kristne medlemmer af samfundet. Men hvad vil det sige, at de giver retfærdighedsprincipper en specifik kristen kvalifikation? Kan man i virkeligheden ikke sige, at John Rawls' idé om en overlappende konsensus netop indebærer, at kristne - og andre religiøse borgere - giver deres specifikke kvalifikation til de fælles retfærdighedsprincipper ved at udlede principperne af deres respektive religiøse livsopfattelse? Men i så fald er der jo ikke brug for en helt ny opfattelse af forholdet mellem en særlig kristen etik og en fælles samfundsetik.

I artikel II taler Nissen om, at religiøse borgere efterlades "with a sense of Entfremdung in relation to the political society", fordi de "are not authentically present in the political debate" (32). Den samme pointe fremføres, så vidt jeg kan se, i behandlingen af abortdiskussionen i Sammenfattende redegørelse p. 138ff. Her hedder det:

[T] he Christian listens to the other and seeks to learn from the other. But ... the Christian can maintain a faithful witness in this conversation. The aim is that we reach a shared understanding (the universal dimension) - be it in the public or elsewhere - but if the Christian (in the course of this conversation) finds it necessary to be explicit or specific about the premises of his convictions, this is fully justified (the specific dimension) (140). 
Også her bruges altså nøglebegreberne "universel” og "specifik". Men hvor er enheden: den kristne modstander af "fri" abort befinder sig jo simpelthen i opposition til den universelle eller bedre fælles lov?

\section{Konklusion}

Ulrik B. Nissens afhandling må hilses velkommen som et meget tiltrængt bidrag til arbejdet med teologisk etik i dette land. Det er især prisværdigt, at Bonhoeffers etik både bringes ind i den hjemlige diskussion og tolkes ind $\mathrm{i}$ aktuelle internationale diskussioner. Man kan som nærværende anmelder være uenig i, hvad man næsten kunne kalde dens kristologiske ekstremisme. Men den udgør en klassisk bestanddel i luthersk teologisk etik og bør som sådan bestandigt præsenteres på ny. Endnu mere relevant er det at forsøge at nyformulere en luthersk etik. Nissen har efter min mening ret $i$, at man her $i$ landet alt for længe har hævdet, at kristendom ikke havde noget med etik at gøre, og da slet ikke med politik. Den opfattelse bygger på en eklatant og efterhånden veldokumenteret fejllæsning af Luthers skrifter, som efter Nissens afhandling ikke mere burde kunne forfægtes.

En nylæsning af Luthers etik lægger naturligt op til en nytænkning af forholdet mellem kristen etik og politik. Igen er selve Nissens problemstilling væsentlig, og han placerer sit arbejde i en af de vigtigste internationale debatter i teologisk etik og politisk filosofi. Ved siden af den fornødne baggrundsinformation om denne debat og dens vigtigste deltagere bringer afhandlingen et originalt synspunkt ind i den.

Men når alt det er sagt, efterlader afhandlingen alligevel en stor forvirring og skuffelse. Hvad er det egentlig, Nissen har på hjerte? Hvad er det for en væsentlig indsigt, den chalkedonensiske kristologi har givet ham, og som han føler sig nødsaget til at bringe ind i den teologisk-etiske debat?

Som antydet ovenfor mener jeg ikke, Nissen tilfører debatten om luthersk etik og om kristendommens rolle i den politiske debat noget overbevisende nyt. Jeg kan følge ham $\mathrm{i}$, at en sondring mellem på den ene side en partikulær kristen etik og på den anden side en universel etik er uholdbar. En luthersk etik indebærer vitterligt en forening af et partikulært - specifikt kristeligt - og et universelt aspekt. Hos Luther selv findes der både en næstekærlighedsetik begrundet i Kristustro (retfærdiggørelse) og en fornuftsetik begrundet i den almene menneskelige natur. Men denne forening har været kendt længe før Nissens afhandling. 
Hvad Nissen egentlig ønsker, er tilsyneladende at sikre en legitim plads for genuine kristelige synspunkter i en offentlig, politisk-etisk debat. Som nævnt har synet på legalisering af abort en vigtig rolle i hans argumentation. Nissen ønsker, at en kristent begrundet modstand mod "fri" abort skal have samme legitimitet i den offentlige debat som en legalisering af abort, sådan som vi fx kender den i Danmark. Det er åbenbart ikke tilstrækkeligt, at den enkelte kristne kvinde og den enkelte kristne sundhedsprofessionelle kan afstå fra at få foretaget eller medvirke ved en svangerskabsafbrydelse. En sådan indstilling og handlemåde ville være et eksempel på, hvad Luther kalder den enkelte kristnes afkald på egne vegne, nemlig afkald på at gøre brug af en retligt sikret fordel. Nissen ønsker, at afvisningen af abort skal have samme legitimitet som alle andre offentlige argumenter om politiske og retlige beslutninger. Hvis vi taler om offentlige argumenter i streng forstand - dvs. argumenter til begrundelse af det offentliges magtudøvelse - må disse argumenter principielt kunne deles af alle borgere. De må, med afhandlingens terminologi, være universelle. Men meget tyder på, at argumenter mod "fri" abort ikke kan have en universel karakter. For at løse det problem konstruerer Nissen begrebet "den differentierede enhed mellem universelt og partikulært": argumentet mod "fri" abort er partikulært - det deles kun af (nogle) kristne -, men vi kan vælge at betegne det som en differentiering af det universelle. Problemet er blot, at den navngivning er helt nytteløs, idet den hverken ændrer det universelle eller det partikulære argument. Men det giver den kristne etiker Urik Nissen udseende af at være i besiddelse af argumenter med ligeså stor overbevisningskraft som hans modstanderes.

Ulrik Nissen har fået sin doktorgrad, og dermed har afhandlingen opfyldt sit væsentlige mål. Men nu må vi forvente, at den teologiske doktor spiller ud med mere substantielle argumenter. 